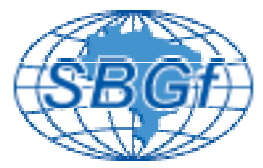

\title{
ELETRORRESISTIVIDADE 3D - RESULTADOS PRELIMINARES
}

\author{
Otávio Coaracy Brasil Gandolfo \\ José Domingos Faraco Gallas \\ INSTITUTO DE GEOCIÊNCIAS - USP
}

\section{Resumo}

Este trabalho mostra os resultados preliminares de um levantamento-piloto, onde foi realizada uma aquisição 3D de eletrorresistividade. O arranjo utilizado foi o pólo-pólo. Os resultados obtidos confirmam a capacidade da técnica em mapear as variações de resistividade nas três dimensões.

Entretanto, a experiência de campo confirmou que a viabilização deste tipo de ensaio de forma a cobrir áreas com dimensões de utilidade prática, só é possível através da utilização de sistemas multi-eletrodos com aquisição automatizada, devido ao tempo despendido para a realização das medidas em campo.

\section{Introdução}

As técnicas usualmente utilizadas no método da eletrorresistividade (sondagem elétrica vertical e caminhamento elétrico) contemplam tanto investigações verticais como laterais, em pontos localizados (SEVs) ou em perfis geralmente dispostos ao longo linhas retas (caminhamento).

A sondagem elétrica vertical (SEV) é capaz de investigar as variações de resistividade ao longo de uma dimensão em profundidade, enquanto que o caminhamento elétrico possibilita o mapeamento de variações laterais e verticais de resistividade ao longo da seção.

Nos anos recentes, vem sendo aplicada a técnica do caminhamento de uma forma automatizada. Através da utilização de um grande número de eletrodos é possível a geração de elevada quantidade de dados em tempo relativamente reduzido. Alguns autores denominam esta técnica, testada em áreas de geologia complexa, de "tomografia elétrica" ou "imageamento 2D de resistividade" (Griffiths \& Barker, 1993).

$\mathrm{Na}$ natureza, entretanto, todas as estruturas geológicas são tridimensionais. Assim sendo, levantamentos 3-D processados por softwares capazes de tratar os dados gerados podem, a princípio, fornecer melhores resultados (Loke, 1999) que os convencionais levantamentos 2D largamente utilizados no meio técnico e acadêmico.

\section{Local do ensaio}

O levantamento-piloto 3D foi realizado no Campus da USP, próximo à Raia Olímpica. Este local funciona como uma área experimental na qual pesquisadores do IG-USP e do IAG-USP vêm desenvolvendo sistemáticos trabalhos de pesquisa ge ológica, geofísica e hidrogeológica de campo.

\section{Execução do levantamento de campo}

Em um levantamento 3D de eletrorresistividade os eletrodos geralmente são dispostos em uma malha quadrada, com o mesmo espaçamento entre eletrodos nas direções $\mathrm{X}$ e $\mathrm{Y}$. $\mathrm{O}$ arranjo comumente utilizado é o pólo-pólo (Loke \& Barker, 1996).

No presente estudo, foi efetuada uma malha composta por 25 eletrodos espaçados de $1 \mathrm{~m}$ entre si constituindo, portanto, um quadrado de dimensão $4 \mathrm{~m}$ x $4 \mathrm{~m}$ (Figura 1).

$\begin{array}{ccccc}1 & 2 & 3 & 4 & 5 \\ 6 & 7 & 8 & 9 & 10 \\ 0 & 0 & 0 & 0 \\ 11 & 12 & 13 & 14 & 15 \\ 0 & 17 & 18 & 19 & 20 \\ 0 & 0 & 0 & 0 \\ 0 & 22 & 23 & 24 & 25\end{array}$

Figura 1 - Geometria dos eletrodos utilizados na aquisição 3D

O arranjo utilizado foi o pólo-pólo. O local onde foi realizado o ensaio permitia a colocação de dois eletrodos fixos (um de corrente e um de potencial) a uma distância "infinitamente" grande (em torno de 100m) da malha quadrada (Foto 1). Desta forma, ficam dispostos sobre a malha os dois eletrodos restantes, sendo um de corrente e o outro de potencial, completando o quadripolo.

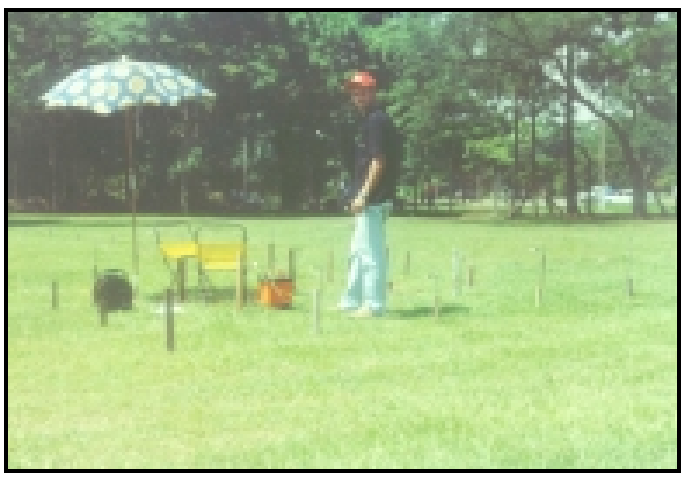

Foto 1 - Local onde foi realizado o ensaio 3D. 
O procedimento de aquisição dos dados utilizou a metodologia proposta por Loke \& Barker (1996), que descreveremos a seguir.

$O$ eletrodo de corrente permanece fixo na estaca 1. Procede-se a leitura do potencial em cada ponto da malha (estaca 2, 3, .., 25). Em seguida, avança-se o eletrodo de corrente para a estaca 2 e efetua-se a leitura do potencial nas posições correspondentes as estacas 3 , 4 até 25 . O procedimento se repete até o fechamento da malha. Note-se que, por uma questão de reciprocidade, é necessário apenas efetuar medidas de potencial nos eletrodos posicionados em estacas de número superior àquela onde está posicionado o eletrodo de corrente.

Nesta configuração pólo-pólo, o número máximo de medidas independentes $\left(n_{\max }\right)$ que pode ser efetuada utilizando-se $n_{e}$ eletrodos, é dado pela seguinte fórmula (Loke \& Barker, 1996):

$$
\mathrm{n}_{\max }=\frac{\mathrm{n}_{\mathrm{e}}\left(\mathrm{n}_{\mathrm{e}}-1\right)}{2}
$$

No presente levantamento, onde foram utilizados 25 eletrodos, tiveram de ser realizadas 300 medidas para o fechamento da malha. O tempo gasto para a execução deste ensaio, utilizando um resistivímetro SAS300B (ABEM Instruments) e com duas pessoas trabalhando em campo, foi de 3,5 horas. Vale salientar-se que à medida que aumenta os pontos da malha, o número de medidas a ser realizado para execução do levantamento cresce de maneira significativa. Ilustrando, caso este levantamento procurasse cobrir uma área ligeiramente maior (exemplo: $6 \mathrm{~m} \times 6 \mathrm{~m}$, correspondendo a uma malha regular de $7 \times 7$ eletrodos, totalizando 49), teríamos de realizar 1176 medidas e a aquisição dos dados poderia levar aproximadamente 14 horas, nas mesmas condições do levantamento ora realizado.

Este fato demonstra a necessidade de utilização de equipamentos multi-eletrodos automatizados para viabilizar a execução de levantamentos 3D cobrindo áreas de dimensões maiores. Para levantamentos práticos viáveis, a execução de malhas menores que 10x10 surtiriam pouco efeito prático, uma vez que a área coberta seria muito pequena (Loke, 1999).

Um levantamento 3D pode ser realizado ainda com os arranjos pólo-dipolo e dipolo-dipolo. Entretanto, como afirma Loke (op.cit.), o arranjo pólo-pólo é o que oferece o maior número de possíveis medidas independentes, se comparado aos outros arranjos, para malhas de dimensões reduzidas (menor que 12 por 12 eletrodos). Além do mais, este arranjo é o que fornece a melhor cobertura horizontal, uma vez que a perda de informação nas bordas é mínima. As desvantagens ficam por conta da baixa resolução e a necessidade de espaço físico para colocação dos eletrodos no "infinito".

\section{Processamento dos dados}

Os valores das resistividades elétricas aparentes foram calculados através da equação 2.

$$
\rho_{\mathrm{a}}=\mathrm{K} \cdot \frac{\Delta \mathrm{V}}{\mathrm{I}}
$$

No caso do arranjo pólo-pólo, a constante geométrica é dada por (eq.3):

$$
\mathrm{K}=2 \pi \mathrm{a}
$$

onde "a" é a distância entre o eletrodo de corrente e o de potencial. O valor da constante "K" foi calculado para cada ponto de medida sobre a malha retangular.

No processamento dos dados foi utilizado o software RES3DINV (Geotomo Software, 2003) que utiliza um método de inversão por mínimos quadrados com suavização restringida ("smoothness-constrained leastsquare inversion").

\section{Resultados obtidos}

A Figura 2 apresenta os resultados do levantamento com os dados processados no programa RES3DINV. O software permite a visualização dos valores de resistividade elétrica modelados (calculados) em "slices" correspondentes a seis níveis de investigação em profundidade.

É nítida a ocorrência de valores mais elevados de resistividade elétrica no primeiro nível, ocorrendo uma diminuição dos mesmos em profundidade. No nível 6 de investigação, as resistividades tendem a aumentar ligeiramente.

Este padrão de distribuição de resistividade em profundidade $\left(\rho_{1}>\rho_{2}<\rho_{3}\right)$ foi igualmente observado em SEV's e levantamentos 2D (caminhamentos elétricos utilizando arranjos dipolo-dipolo e pólo-dipolo) realizados no mesmo local.

\section{Conclusões}

Os resultados obtidos neste ensaio-piloto mostraram a capacidade da técnica em mapear variações de resistividade em planta (eixos $X$ e $Y$ ) e em profundidade (eixo Z), podendo encontrar diversas aplicações em geotecnia e em meio ambiente.

Entretanto, de forma a cobrir áreas com dimensões razoáveis, faz-se necessária a utilização de elevado número de eletrodos na malha de investigação, o que aumenta de forma excessiva o tempo de aquisição dos dados em campo.

A viabilização de levantamentos $3 D$ de resistividade em situações práticas reais está, de fato, condicionada à utilização de equipamentos multi-eletrodos e/ou com aquisição automatizada (Dahlin \& Bernstone, 1997). 


\section{Agradecimentos}

Ao técnico Paulo do IG-USP, pelo auxílio nos trabalhos de campo.

\section{Referências Bibliográficas}

Dahlin, T., Bernstone, C. 1997. A roll-along technique for 3D resistivity data acquisition with multi-electrode arrays. In: Proceedings of the Symposium on the Application of Geophysics to Engineering and Environmental Problems (SAGEEP'97). Expanded Abstracts, v.II, p.927-932.

Geotomo Software, 2003. RES3DINV ver.2.13 Geoelectrical Imaging 2D \& 3D, 63pp (disponível em www.geoelectrical.com).

Griffiths D. H., Barker, R. D., 1993. Two-dimensional resistivity imaging and modelling in areas of complex geology. Journal of Applied Geophysics, 29: 211-226.

Loke, M. H., Barker, R. D., 1996. Practical techniques for 3D resistivity survey and data inversion. Geophysical Prospecting, 44: 499-523.

Loke, M. H., 1999. Electrical imaging surveys for environmental and engineering studies: a practical guide to 2-D and 3-D surveys. Notes, 61pp (disponível em www.abem.se) 

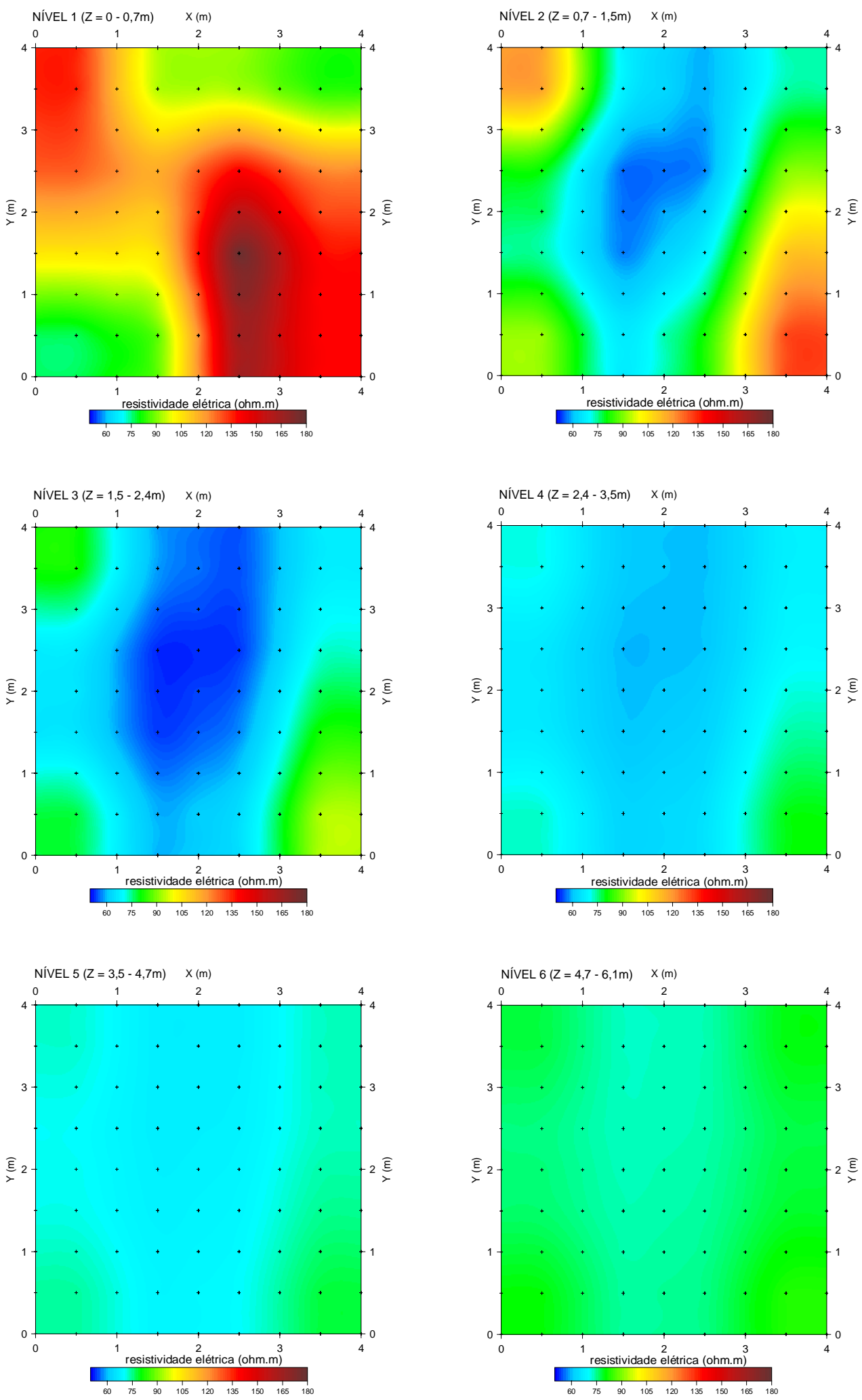

Figura 2 - Resultado do levantamento 3D recobrindo uma área de $16 \mathrm{~m}^{2}$ (4m x 4m) apresentado em seis níveis de investigação em profundidade 